\title{
Evaluación de un sistema automatizado de siembra de orinas para urocultivos
}

\author{
Verónica Bustamante, Paulina Meza, Juan C. Román y Patricia García
}

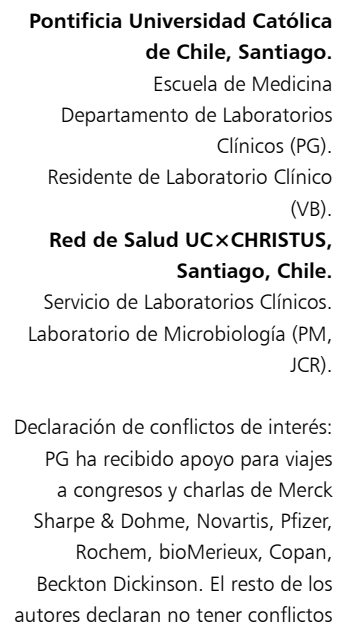

Declaración de conflictos de interés: PG ha recibido apoyo para viajes a congresos y charlas de Merck Sharpe \& Dohme, Novartis, Pfizer,

Rochem, bioMerieux, Copan,

Beckton Dickinson. El resto de los autores declaran no tener conflictos de interés.

Fuente de financiamiento: Fondo SENTRY Laboratorio de Microbiología, Departamento de Laboratorios Clínicos.

Recibido: 20 de febrero de 2014 Aceptado: 5 de agosto de 2014

Correspondencia a: Patricia García Cañete pgarcia@med.puc.cl

\section{Introducción}

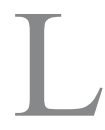

a automatización de los laboratorios nació como una solución a la sobrecarga de trabajo producida por una creciente solicitud de exámenes médicos ${ }^{1}$. Los beneficios de la incorporación de nuevas tecnologías en los procesos han sido muchos; aumentar la productividad, disminuir los costos, mejorar la estandarización, la reproducibilidad y la trazabilidad a través de la conexión a sistemas informáticos. Esto ha contribuido a tener un sistema más eficiente y seguro para el paciente ${ }^{1}$. El concepto de automatización ha ido evolucionando y actualmente pretende integrar las distintas áreas de trabajo bajo el concepto de "Total Laboratory Automation"2. El objetivo final es lograr la comunicación entre los distintos sistemas de automatización, de manera de potenciar los beneficios de cada sistema mediante la integración.

Los laboratorios de microbiología han experimentado un aumento similar en la carga de trabajo al resto de las áreas de laboratorio pero, dada su complejidad, el desarrollo e incorporación de nuevas tecnologías han sido más lentos ${ }^{2-4}$. Se sabe que la etapa pre analítica ocupa una parte importante de la carga de trabajo, la inoculación de las muestras en placas de agar consume el $25 \%$ del tiempo del personal dedicado a la recepción y procesamiento inicial de las muestras ${ }^{5}$. Actualmente existen equipos con distintos grados de automatización para la siembra de muestras que se comunican con el sistema informático, seleccionan los medios de cultivo, inoculan, siembran, y etiquetan las placas obtenidas. Sistemas como WASP ${ }^{\circledR}$ (Walk Away Specimen Processor) de Copan Diagnostics, InoqulA ${ }^{\mathrm{TM}}$ de BD Kiestra ${ }^{\mathrm{TM}}$ y PREVITM Isola de BioMerieux permiten usar distintos tipos de muestras, utilizan diferentes metodologías de siembra. Han demostrado que son más reproducibles que la siembra manual, que permiten obtener un mayor número de colonias aisladas y además disminuyen la carga de trabajo ${ }^{2,5-8}$. La elección del sistema va a depender de los requerimientos de cada laboratorio, tipo y número de muestras procesadas, compatibilidad con el sistema informático, entre otros ${ }^{5,9}$.

En nuestro país no se ha evaluado la implementación de estos sistemas pre analíticos en el área de microbiología, por lo que el objetivo de este trabajo es evaluar el desempeño de un sistema automatizado de siembra de urocultivos y la concordancia con la siembra manual convencional en el recuento semicuantitativo de colonias.

\section{Materiales y Métodos}

Se realizó una comparación de manera prospectiva entre las placas de urocultivo obtenidas por nuestro 
método habitual de siembra y las obtenidas por el sistema PREVITM Isola, de bioMerieux. Durante 10 días se recolectaron orinas seleccionadas al azar, provenientes desde las tomas de muestra ambulatoria al laboratorio de microbiología del Departamento de Laboratorios Clínicos de la Red de Salud UC. La toma de muestra fue realizada en frasco estéril sin preservante.

A diario se realizó la siembra de las orinas recolectadas, según el protocolo habitual del laboratorio, que consiste de la siembra de $1 \mu \mathrm{L}$ con asa calibrada en una biplaca de agar chromID ${ }^{\circledR} \mathrm{CPS} \circledast /$ Columbia $\mathrm{CNA}+5 \%$ de sangre de cordero según recomendaciones del Cumitech de siembra con dos medios de cultivo ${ }^{12}$. CPS $®$ es un medio cromogénico selectivo que permite la identificación rápida de Escherichia coli, Proteus spp, Enterococcus spp, Klebsiella, Enterobacter, Serratia y Citrobacter, mientras el medio Columbia CNA es un medio selectivo para fastidiosos, que permite además la detección de hemolisis. En paralelo se sembró en una placa de agar chromID ${ }^{\mathrm{TM}}$ CPS ${ }^{\circledR}$ con el sistema automatizado de pipeta y cepillo de PREVITM Isola, que mediante comunicación con el sistema informático selecciona las placas, inocula $10 \mu \mathrm{L}$ con una pipeta, esparce con una peineta y etiqueta las placas obtenidas. El número de muestras procesadas alcanza las 180 placas/h según lo reportado por el fabricante. Se usó medios diferentes con ambos sistemas debido a que el equipo siembra $10 \mu \mathrm{L}$ de muestra, no permite siembra de biplacas con $1 \mu \mathrm{L}$ como se hace de manera habitual y además no existe una lectura semi cuantitativa validada para este tipo de placas, pero sí para las de agar CPS®. Las placas se incubaron durante $18 \mathrm{~h}$ a $35^{\circ} \mathrm{C}$. Al día siguiente fueron ingresadas a la rutina del laboratorio y evaluadas en conjunto con el sedimento u orina completa, en los casos en que éste se había solicitado.

\section{Recuento e identificación de las colonias en los urocultivos}

- Recuento método manual: el recuento de colonias en las biplacas de siembra manual se realiza multiplicando el $\mathrm{N}^{\mathrm{o}}$ de colonias obtenidas por cien.

- Recuento sistema automatizado: distintos autores han validado una lectura del recuento de colonias para PREVITM Isola, dado que el volumen y el método de siembra es diferente ${ }^{1,7,10}$. Esta se realiza en base al número de cuadrantes con desarrollo de colonias, como se observa en la Figura 1. Los rangos obtenidos con esta metodología son: $<10.000 \mathrm{ufc} / \mathrm{ml}, 10.000 \mathrm{a}$ $50.000 \mathrm{ufc} / \mathrm{ml}, 50.000-100.000 \mathrm{ufc} / \mathrm{ml} \mathrm{y}>100.000$ $\mathrm{ufc} / \mathrm{ml}$.

- Identificación de especie: se realizó con el sistema habitual del laboratorio, que consiste en el uso de espectrometría de masa, MALDI-TOF MS (Bruker Daltonics, Bremen, Alemania).

\section{Interpretación de resultados de los urocultivos}

Independiente del método de siembra utilizado, cuando una muestra es obtenida por segunda micción, recolector o sonda a permanencia, se considera según las recomendaciones internacionales ${ }^{12}$ :

Urocultivo positivo: el hallazgo de un microorganismo en un recuento $\geq 10.000 \mathrm{ufc} / \mathrm{mL}$ con un sedimento urinario con al menos 10 leucocitos/uL o el hallazgo de dos microorganismos en que alguno de ellos presente un predominio claro con un recuento $\geq 100.000$ con al menos 10 leucocitos/uL.

Urocultivo negativo: todo recuento menor a 10.000 $\mathrm{ufc} / \mathrm{mL}$.

Muestras polimicrobianas: la presencia de tres o más microorganismos, independiente del número de leucocitos.

Frente al caso de obtener un recuento significativo $(>10.000 \mathrm{ufc} / \mathrm{ml})$ sin colonias aisladas, se realiza una resiembra del cultivo para obtener colonias aisladas y realizar un estudio de identificación y susceptibilidad confiables.

\section{Comparación de resultados}

Para el análisis estadístico y la evaluación de la concordancia entre ambos métodos se utilizó el programa (C2013 GraphPad Software (GraphPad QuickCalcs). Se obtuvo el porcentaje de concordancias observadas y el valor de Kappa (к) para evaluar la concordancia entre: resultados negativos y positivos; entre muestras polimicrobianas y no polimicrobianas; entre los tres resultados (positivos,

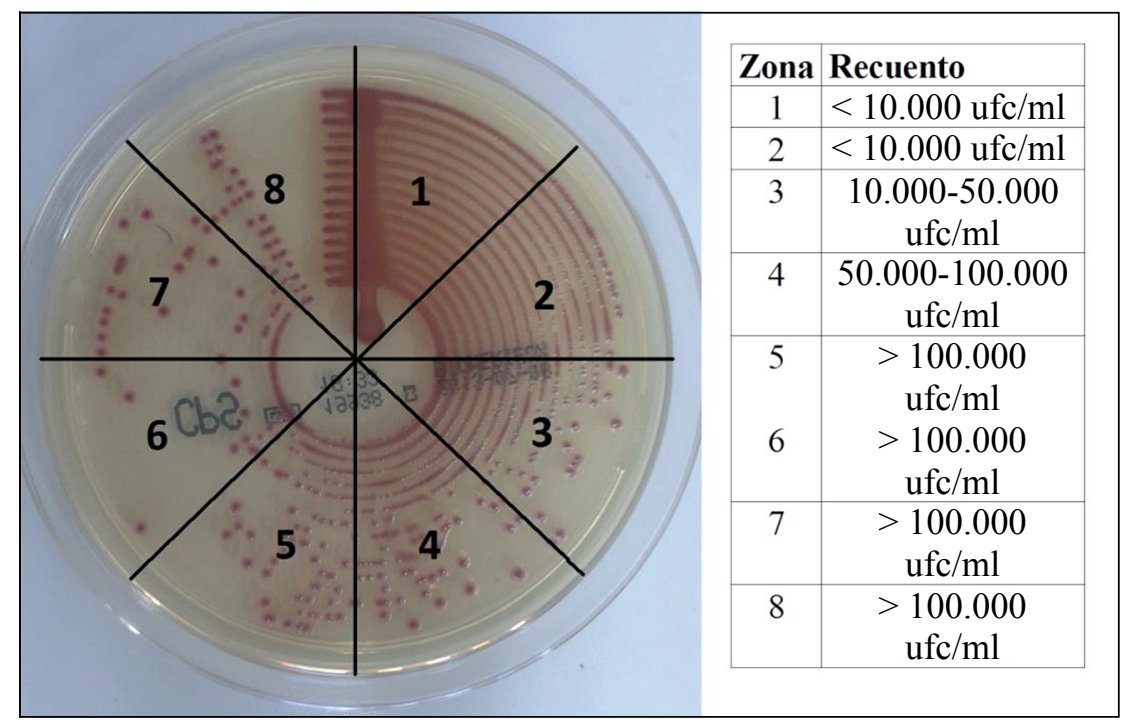

Figura 1. Siembra obtenida y recuento para placas sembradas con PREVI ${ }^{\mathrm{TM}}$ Isola. El recuento semi cuantitativo se realiza dividiendo la placa en ocho zonas y observando las áreas con crecimiento de colonias. La zona de inoculación corresponde a la línea entre las áreas 8 y 1, a partir del cual se distribuye la muestra. La interpretación del recuento semi cuantitativo se realiza observando hasta que zona hubo desarrollo de colonias, en el ejemplo de la foto el crecimiento correspondía a $>100.000 \mathrm{ufc} / \mathrm{mL}$. 


\begin{tabular}{|c|c|}
\hline Карра & Concordancia \\
\hline$<0$ & Sin concordancia (poor) \\
\hline $0,01-0,2$ & Concordancia leve (slight) \\
\hline $0,21-0,4$ & Concordancia aceptable (fair) \\
\hline $0,41-0,6$ & Concordancia moderada (moderate) \\
\hline $0,61-0,8$ & Concordancia sustancial (substantial) \\
\hline $0,81-0,99$ & Concordancia casi perfecta (almost perfect) \\
\hline
\end{tabular}

\begin{tabular}{|c|c|c|c|c|c|}
\hline & \multicolumn{5}{|c|}{ Resultados con siembra mediante PREVI ${ }^{\mathrm{TM}}$ Isola } \\
\hline & & Positivos & Negativos & $\begin{array}{c}\text { Muestras } \\
\text { polimicrobianas }\end{array}$ & Total \\
\hline \multirow{4}{*}{$\begin{array}{l}\text { Resultados } \\
\text { con siembra } \\
\text { convencional }\end{array}$} & Positivos & 89 & 2 & 0 & 91 \\
\hline & Negativos & 0 & 394 & 0 & 394 \\
\hline & Muestras polimicrobianas & 3 & 0 & 7 & 10 \\
\hline & Total & 92 & 396 & 7 & 495 \\
\hline
\end{tabular}

Número de concordancias: 490 (98,9\%). $\kappa=0,97$ (IC 95\% 0,94-0,99), valor- $p=0,013$.

Tabla 3. Comparación de los resultados obtenidos con siembra convencional y PREVI $^{\text {Tm }}$ Isola en el subgrupo de los positivos y negativos

\begin{tabular}{llcccc} 
& & \multicolumn{3}{c}{$\begin{array}{c}\text { Resultados con siembra mediante PREVI } \\
\text { Positivos }\end{array}$} & Isola \\
Negativos & Total \\
$\begin{array}{l}\text { Resultados } \\
\text { con siembra } \\
\text { convencional }\end{array}$ & Positivos & Negativos & 89 & 2 & 91 \\
\cline { 2 - 3 } & Total & 0 & 394 & 394 \\
\hline
\end{tabular}

Número de concordancias: $483(99,6 \%) . \kappa=0,99$ (IC 95\% 0,97-1,00), valor-p $=0,01$

negativos y muestras polimicrobianas); y entre rango de recuentos. El porcentaje de concordancias observadas corresponde a:

( $\mathrm{N}^{\mathrm{o}}$ concordancias observadas $/ \mathrm{N}^{\mathrm{o}}$ resultados $) \times 100$

Para kappa (к) se estableció como meta un valor $>0,81$, es decir, una concordancia casi perfecta en todos los cálculos ${ }^{11-13}$. Este autor propone para la interpretación de kappa seis rangos, que se observan en la Tabla 1, en que el nivel más alto de concordancia es el de la concordancia casi perfecta.

Los resultados esperados para las comparaciones fueron:

- Recuento de colonias: porcentaje de concordancias observadas $\geq 90 \%$, tanto en urocultivos considerados positivos (10.000-100.000 ufc/ml), como negativos.
- Muestras polimicrobianas: porcentaje de concordancias observadas $\geq 98 \%$, definidos como la presencia de tres o más microorganismos:

- Microorganismos recuperados: porcentaje de concordancias observadas $\geq 98 \%$ (recuperación de las mismas especies).

- Necesidad de resiembra desde la placa: disminución de la necesidad de resiembra para obtener colonias aisladas y poder realizar una adecuada identificación y susceptibilidad a los antimicrobianos. El análisis estadístico de la comparación entre ambos métodos se realizó mediante test de $\chi^{2}$.

En el caso de muestras discordantes (para resultados positivos, negativos o muestras polimicrobianas) se consideró el resultado del sedimento urinario en el análisis.

\section{Resultados}

Se obtuvieron 495 orinas provenientes de segunda micción, recolector y cateterismo vesical. De este total, $18,4 \%$ (n: 91 ) fueron positivas, $2 \%$ (n: 10) fueron muestras polimicrobianas y 394 (n: 79,6\%) fueron negativas. De los urocultivos positivos, $84,6 \%$ (77/91) presentaron recuentos altos (> $100.000 \mathrm{ufc} / \mathrm{mL})$ y $15,4 \%$ (14/91) presentaron recuento entre 10.000 y $100.000 \mathrm{ufc} / \mathrm{mL}$.

Los microrganismos identificados en los urocultivos positivos fueron: E. coli en 69 muestras $(75,8 \%)$, Klebsiella pneumoniae en 7 (7,7\%), Enterococcus faecalis en 7 (7,7\%), Streptococcus agalactiae en 5 $(5,5 \%)$, Proteus mirabilis en $2(2,2 \%)$ y Comamonas spp en una muestra $(1,1 \%)$.

La comparación entre ambos sistemas de siembra se observa en la Tabla 2. Del total de 495 muestras analizadas, 490 fueron concordantes en resultados positivos, negativos y muestras polimicrobianas $(98,99 \%)$. Esto corresponde a una correlación casi perfecta, con un valor de $\kappa$ de 0,969, IC 95\% 0,943-0,996 y valor-p de 0,013.

Considerando sólo los urocultivos positivos y negativos (Tabla 3), el porcentaje de resultados concordante también es casi perfecto $(483 / 485=99,59 \%)$ con un $\kappa$ de 0,986 , IC $95 \%$ 0,967-1,005 y valor-p 0,010. Del mismo modo, la concordancia entre urocultivos con y sin muestras polimicrobianas (Tabla 4) fue de $99,39 \%$ (492/495), con un valor $\kappa$ casi perfecto, pero menor que en los resultados anteriores, esto es, 0,821 , IC $95 \% 0,621$ 1,020 y valor $\mathrm{p}$ de 0,102 .

Adicionalmente se calculó la concordancia entre el recuento obtenido por el método de siembra convencional y los rangos obtenidos por la siembra automatizada (Tabla 5) en aquellos urocultivos positivos y negativos (n: 485). Se obtuvo una concordancia de $98,97 \%$ (480/485) con un valor de $\kappa$ de 0,967 ; IC 0,939-0,995 y valor-p de 0,014 . Todos los urocultivos negativos (394/394) y 
98,7\% (76/77) de los urocultivos positivos con recuentos $>100.00 \mathrm{ufc} / \mathrm{mL}$ fueron concordantes. Entre los urocultivos con recuentos entre 10.000 y 100.000 (n: 15) hubo 10 concordancias. Las muestras con recuentos discordantes se muestran en la Tabla 6, donde se observa que la siembra manual obtiene recuentos más altos que la siembra automatizada, resultando dos muestras negativas por el método automatizado y con bajo recuento en el sistema convencional. Esta Tabla muestra también los resultados de los sedimentos urinarios, en caso de encontrarse disponibles. Hubo dos muestras (muestra $\mathrm{N}^{0} 3$ y $\mathrm{N}^{0} 5$ ) que hubiesen sido informados como negativas por PREVITM Isola en las que no se disponía de sedimento urinario. En el caso de las muestras $\mathrm{N}^{\circ} 1$ y $\mathrm{N}^{\mathrm{o}} 2$ destaca que en ambos casos el recuento de leucocitos y la presencia de bacterias en el sedimento urinario fue escaso, correspondiendo en ambos a E. faecalis. El caso $\mathrm{N}^{\mathrm{o}} 4$, también presentó al sedimento un escaso número de bacterias, pero abundantes leucocitos.

En cuanto a los microorganismos aislados, en 90 de $91(99,76 \%)$ hubo coincidencia en los microorganismos. La discordancia fue en una muestra en que se obtuvo $E$.

Tabla 4. Comparación de los resultados obtenidos con siembra convencional y PRE$\mathrm{VI}^{\mathrm{Tm}}$ Isola, para el subgrupo de las muestras polimicrobianas

\begin{tabular}{|c|c|c|c|c|}
\hline & \multicolumn{4}{|c|}{ Resultados con siembra mediante PREVI ${ }^{T M}$ Isola } \\
\hline & & $\begin{array}{c}\text { Muestras } \\
\text { polimicrobianas }\end{array}$ & $\begin{array}{c}\text { Muestras no } \\
\text { polimicrobianas }\end{array}$ & Total \\
\hline \multirow{3}{*}{$\begin{array}{l}\text { Resultados } \\
\text { con siembra } \\
\text { convencional }\end{array}$} & Muestras polimicrobianas & 7 & 3 & 10 \\
\hline & Muestras no polimicrobianas & 0 & 485 & 485 \\
\hline & Total & 7 & 488 & 495 \\
\hline
\end{tabular}

Número de concordancias: 492 (99,39\%). $\kappa=0,82$ (IC 95\% 0,62-1,02), valor-p $=0,102$.

Tabla 5. Comparación de los recuentos obtenidos con siembra convencional y PREVI ${ }^{\mathrm{m}}$ Isola. Se categorizaron los recuentos convencionales para poder tabular y comparar los datos obtenidos con ambos métodos

\begin{tabular}{|c|c|c|c|c|c|}
\hline & \multicolumn{5}{|c|}{ Recuento en placa PREVI' ${ }^{\mathrm{m}}$ Isola } \\
\hline & & $<10.000 \mathrm{ufc} / \mathrm{ml}$ & $10.000-50.000 \mathrm{ufc} / \mathrm{ml}$ & $50.000-100.000 \mathrm{ufc} / \mathrm{ml}$ & $>100.000 \mathrm{ufc} / \mathrm{m}$ \\
\hline \multirow{5}{*}{$\begin{array}{l}\text { Recuento en } \\
\text { placa siembra } \\
\text { convencional }\end{array}$} & $<10.000 \mathrm{ufc} / \mathrm{ml}$ & 394 & 0 & 0 & 0 \\
\hline & $10.000-50.000 \mathrm{ufc} / \mathrm{ml}$ & 2 & 3 & 0 & 0 \\
\hline & $50.000-100.000 \mathrm{ufc} / \mathrm{ml}$ & 0 & 2 & 7 & 0 \\
\hline & $>100.000 \mathrm{ufc} / \mathrm{ml}$ & 0 & 1 & 0 & 76 \\
\hline & & & & Total & 485 \\
\hline
\end{tabular}

Tabla 6. Descripción de las discordancias observadas en los recuentos

\begin{tabular}{|c|c|c|c|c|}
\hline n & Microorganismo & $\begin{array}{c}\text { Recuento en ufc/mL, en medio chromID } ₫ C P S \AA / \\
\text { Columbia CNA }+5 \% \text { de sangre de cordero con } \\
\text { siembra convencional }\end{array}$ & $\begin{array}{l}\text { Recuento en ufc/mL, de placa CPS }{ }^{\circledR} \\
\text { sembrada con PREVI }{ }^{\top \mathrm{m}} \text { Isola }\end{array}$ & $\begin{array}{c}\text { Sedimento urinario } \\
\text { (Valores de referencia: Leucocitos } \\
\text { hasta 15/uL, eritrocitos hasta 10/uL) }\end{array}$ \\
\hline 1 & E. faecalis & 60.000 & $10.000-50.000$ & $\begin{array}{l}\text { Eritrocitos: 4/uL } \\
\text { Leucocitos: } 5 / \mathrm{uL} \\
\text { Células descamativas: }+ \\
\text { Bacterias: }(+) \\
\text { Mucus: }(++)\end{array}$ \\
\hline 2 & E. faecalis & $>100.000$ & $10.000-50.000$ & $\begin{array}{l}\text { Eritrocitos:1/uL } \\
\text { Leucocitos: } 15 / \mathrm{uL} \\
\text { Células descamativas: } 1 \\
\text { Bacterias: }(+) \\
\text { Mucus: }( \pm)\end{array}$ \\
\hline 3 & E. coli & 13.000 & $<10.000$ & Sin sedimento solicitado \\
\hline 4 & E. coli & 80.000 & $10.000-50.000$ & $\begin{array}{l}\text { Eritrocitos: 4/uL } \\
\text { Leucocitos: 108/uL } \\
\text { Células descamativas: (-) } \\
\text { Bacterias: (+) } \\
\text { Mucus: (-) }\end{array}$ \\
\hline 5 & Comamonas spp & 15.000 & $<10.000$ & Sin sedimento solicitado \\
\hline
\end{tabular}


coli y $S$. aureus, ambos en un recuento de $>100.000 /$ $\mathrm{ml}$ ufc, por el método convencional, mientras que por el método automatizado sólo hubo desarrollo de $E$. coli en $>100.000 \mathrm{ufc} / \mathrm{ml}$.

El número de resiembras que fue necesario realizar para obtener colonias aisladas fue significativamente menor en el sistema automatizado (1/91) en comparación con el método convencional (11/91), lo que corresponde a 1,1 y $12,1 \%$ respectivamente.

\section{Discusión}

Este trabajo muestra la primera evaluación de un sistema automatizado para la siembra de muestras microbiológicas en Chile. Este sistema permite la siembra de distintas muestras líquidas en placas de agar, pero dado que en nuestro laboratorio la principal carga de trabajo son los urocultivos se decidió evaluar solamente estas muestras. Los resultados obtenidos reflejan una excelente concordancia entre el sistema de siembra manual y el automatizado en términos de resultados positivos de los urocultivos y sus recuentos, resultados negativos y muestras polimicrobianas. Además de las ventajas previamente descritas en la introducción, este sistema permite disminuir en forma significativa las resiembras para obtener colonias aisladas, con lo que disminuye el tiempo de entrega de los resultados y el costo asociado a la re-siembra; sin embargo, dado que los laboratorios de microbiología de Chile siembran más de una muestra de orina por placa y en este estudio se ocupa una placa por paciente pues el equipo no permite hacerlo de otra forma, se debe considerar el aumento en el consumo de medios de cultivos.

En las discordancias entre recuentos es importante destacar que éstas se presentan con recuentos bajos de $\mathrm{N}^{\mathrm{o}}$ de colonias y, en los casos en que se dispuso de sedimento, se confirmó una escasa cantidad de bacterias y leucocitos, con excepción de la muestra $\mathrm{N}^{\circ} 4$, en que probablemente la diferencia en el recuento no hubiese cambiado la conducta médica.

Una limitación del estudio es las diferencias en los medios de cultivo utilizados con ambos métodos. Sin embargo, se obtuvo una alta concordancia en los parámetros evaluados, salvo en una muestra en que además de $E$. coli se recuperó $S$. aureus en el medio con agar Columbia CNA $+5 \%$ de sangre de cordero. Dado que ambos métodos obtienen resultados comparables utilizando sólo un medio CPS ${ }^{2}$, el uso de sólo este medio podría representar una buena alternativa de siembra con una disminución de los costos, lo que debe ser evaluado en el futuro.

En este estudio no se evaluaron algunos potenciales beneficios del uso de un sistema automatizado como son la disminución del tiempo necesario para la siembra que sí ha sido evaluado en otros estudios ${ }^{1,10}$, lo que sería de cercano a $20 \%$. Otro beneficio que ofrecería la implementación de un sistema automatizado es la disminución del error asociado a la identificación de las muestras y mejorar la estandarización. Estos elementos y la alta concordancia obtenida entre los dos sistemas de siembra, asociado a una menor necesidad de resiembra, nos indica que el sistema automatizado PREVITM Isola representa una buena alternativa para la automatización de las siembras de orina.

\section{Resumen}

Introducción: Los sistemas automatizados han facilitado el flujo de trabajo, mejorado la estandarización, la trazabilidad, disminuido el error humano y la carga de trabajo en los laboratorios. A pesar de que la microbiología ha permanecido poco automatizada, en los últimos años han aparecido nuevas herramientas para la automatización de la etapa pre analítica. Objetivos: Evaluar el desempeño de un sistema automatizado de siembra de urocultivos y la concordancia con la siembra manual convencional en el recuento semicuantitativo de colonias. Materiales y Métodos: 495 muestras de orinas fueron sembradas según nuestro protocolo habitual y comparadas con las placas de CPS ${ }^{\circledR}$ obtenidas con PREVITM Isola en cuanto a positividad/negatividad, muestras polimicrobianas, especies de bacterias aisladas, recuentos y necesidad de resembrar. Resultados: Hubo concordancia en 98,97\% de los positivos y negativos, en 99,39\% de las muestras polimicrobianas, en $99,76 \%$ de las especies aisladas y en $98,56 \%$ de los recuentos. La necesidad de resiembra disminuyo de $12,1 \%$ a un $1,1 \%$ usando este sistema automatizado. Discusión: El desempeño de PREVITM Isola fue el esperado, mejorando el aislamiento bacteriano y el tiempo requerido y representa una buena herramienta para la automatización de laboratorios.

\section{Referencias bibliográfícas}

1.- Chapin K C, Andrade M, Andrea S B, Tellier L A. Solutions for implementation of the automated Previ Isola plating instrument in the clinical laboratory. $112^{\text {th }}$ General Meeting ASM. San Francisco, June 16-19, 2012.
2.- Young S D. Laboratory automation:smart strategies and practical applications. Clin Chem 2000; 46.5: 740-5.

3.- Dumitrescu O, Dauwalder O, Lina G. Present and future automation in bacteriology. Clin Microbiol Infect 2011; 17.5: 649-50

4.- Mulatero F, Bonnardel V, Micolaud C. The way forward for fast microbiology. Clin Microbiol Infect 2011; 17 (5): 661-7.

5.- Greub G, Prod'hom G. Automation in clinical bacteriology: what system to choose? Clin Microbiol Infect 2011; 17 (5): 655-60.

6.- Bourbeau P P, Swartz B L. First evaluation of the WASP, a new automated microbiology 
plating instrument. J Clin Microbiol 2009; 47: 1101-6.

7.- Glasson J H, Guthrie L H, Nielsen D J, Bethell F A. Evaluation of an automated instrument for inoculating and spreading samples onto agar plates. J Clin Microbiol 2008; 46: 1281-4.

8.- Mischnik A, Mieth M, Busch C J, Hofer S, Zimmermann S. First evaluation of automated specimen inoculation for wound swab samples by use of the Previ Isola system compared to manual inoculation in a routine laboratory: finding a cost-effective and accurate approach. J Clin Microbiol 2012; 50 (8): 2732-6.

9.- Talec R. (2010). L'automatisation en bactériologie, nouvelle priorité des laboratoires? IRBM News 2010; 31(4): 15-20.

10.- Verhoef-Verhage A P J, van Boxtel W C M, van de Wijdeven-Evers. The Previ Isola System for automated streaking of patient materials. $19^{\text {th }}$ ECCMID, European Congress of Clinical Microbiology and Infectious Diseases. Helsinki, Finland 16-19 may 2009, P 890.
11.- Viera A J, Garrett J M. Understanding interobserver agreement: the kappa statistic. Fam Med 2005; 37 (5): 360-3

12.- McCarter Y S, Burd E M, Hall G S, Zervos M. 2009. Cumitech 2C, Laboratory Diagnosis of Urinary Tract Infections. Coordinating ed., S. E. Sharp. ASM Press, Washington, DC.

13.- Cerda J, Villarroel del P L. Evaluación de la concordancia inter-observador en investigación pediátrica: Coeficiente de Kappa. Rev Chilena Pediatr 2008; 79 (1), 54-8. 